\title{
Arranjos e Sistemas Produtivos e Inovativos Locais - As Possibilidades do Conceito na Constituição de um Sistema de Planejamento para a Amazônia*
}

\section{Francisco de Assis Costa}

Professor e Pesquisador do Núcleo de Altos Estudos Amazônicos (NAEA-UFPA) e Coordenador Geral de Planejamento Estratégico e Gestão da Agência de Desenvolvimento da Amazônia (ADA)

\section{RESUMO}

$\mathrm{O}$ artigo discute a possibilidade da noção de Arranjos e Sistemas Produtivos e Inovativos Locais (ASPIL) se constituir em conceito-chave de tais iniciativas. Indica que, para tanto, ela terá que permitir a leitura integrada das escalas (micro, meso e macro) e das esferas (econômica, social e ecológica) da economia regional e seu desenvolvimento e, assim, poder se constituir em referência para a montagem de mecanismos de abertura do processo decisório, para pactuar prioridades para o planejamento do desenvolvimento e para o acompanhamento do processo de intervenção de governo. $\mathrm{O}$ artigo discute tais possibilidades a partir das précondiçôes necessárias e dos encaminhamentos institucionais concretos em nível de governo e de outros atores relevantes.

Palavras-Chave | Amazônia; Inovações Institucionais; Desenvolvimento Regional; Sustentabilidade

Códigos JEL | O10; O17

\footnotetext{
Apresentado no Seminário Perspectivas e Políticas para Arranjos e Sistemas de Inovação e Aprendizado na América Latina, realizado pela RedeSist de 22 a 24 de setembro de 2004, no Rio de Janeiro, o trabalho se realizou no âmbito do projeto Sistemas Produtivos e Inovativos Locais de MPME: uma nova estratégia de ação para o Sebrae RedeSist. Agradeço as sugestões valiosas dos pareceristas anônimos, as quais deram ao artigo a consistência que ora apresenta.
} 


\section{ABSTRACT}

The article discusses the possibility of the concept of Local Productive and Innovative Arrangements Systems to constitute a key-concept of such undertakings. It indicates that, to achieve such status, that concept will have to allow for an integrated reading of scales (micro, meso and macro) and of spheres (economic, social and ecological) of the regional economy and its development. Thus, it could constitute a reference for building mechanisms to open the decision process, for agreeing on priorities in the regional development planning and for the monitoring of government interventions. The article discusses such possibilities starting from the necessary preconditions and from the concrete institutional measures and actions by both the government and other important agents.

Keywords | Amazonian Region; Institutional Innovations; Regional Development; Sustainability

\section{JEL-Codes I O10; O17}

\section{Introdução}

As ciências da sociedade, nos paradigmas que conformam suas diversas disciplinas como ciências normais, já estabelecidas (Kuhn, 1982), distinguemse de forma radical das ciências da natureza. Ao contrário do que ocorre nestas, onde o conhecimento sobre a natureza é propriedade exclusiva de seu sujeito (a sociedade) naquelas não há como distinguir sujeito e objeto do conhecimento. A sociedade - quer vista como estrutura transcendente aos indivíduos, quer como resultado da subjetividade destes - e sua história - seja interpretada como dinâmica contraditória, porém evolutiva, de condições objetivas, seja vista como evolução linear derivada do progresso gradual do homem e sua racionalidade são, respectivamente, o ponto de partida e de chegada de suas preocupaçôes e, 
ao mesmo tempo, o locus onde constróem edificaçôes cumulativas de conhecimentos constantemente acionados como forças ativas da própria realidade que procuram explicar.

Assim, todo conhecimento que se forma como ciência $(\log o)$, é imediatamente passível de absorção social como techné, constituindo-se em força de determinação da própria história. As formas como a sociedade absorve o que se compreende dela ou de sua base natural independe da intenção de quem produziu o conhecimento: o que é visto pelo seu produtor como pura ciência, pode ser, como techné, mero instrumento de poder, negando, por vezes, na prática social resultante, situações que se pretenderiam afirmar ou afirmando o status quo cuja negação era em princípio a intenção. É tarefa adicional das ciências da sociedade compreender como, validando que devir, a dinâmica social absorve os conhecimentos, incluindo aqueles por elas próprias gerado. É função dela, pois, a avaliação crítica do seu próprio papel.

Este artigo discute uma situação particular dessa convivência, a partir da observação de aspectos da passagem de uma noção produzida no campo científico, ' a noção de Arranjos e Sistemas Produtivos e Inovativos Locais (ASPIL), para o campo político ${ }^{2}$ - para a orientação da intervenção política na realidade amazônica.

A Amazônia reveste-se de particularidades. Espera-se, em perspectivas local, nacional e mundial, que o ideário do desenvolvimento sustentável - um desenvolvimento moderno por se fazer aliando eficiência econômica com eqüidade social e trato cuidadoso da base natural (Sachs, 1993; Alier, 1994) - venha a orientar as políticas públicas para a região.

Destaca-se, contudo, como obstáculo a isso, um ambiente institucional conservador, cujas abordagens das possibilidades de desenvolvimento da região

\footnotetext{
Os campos são espaços sociais onde agem pessoas particulares, com posições sociais e habitus - segundo Bourdieu (1989:61), disposições duráveis, incorporadas, quase naturais - próprios, mediadas por instituições estruturalmente articuladas em oposição ou complementaridade pelas regras que fazem o próprio campo: aquelas que regulam o processo de acumulação do capital específico respectivo. O capital específico do campo científico é para Bourdieu, a autoridade científica (Bourdieu, 1994:193), cuja acumulação, acrescento eu (Costa, 1998:21), faz-se na forma elementar desse capital: o mérito científico, expresso em bônus (atestados) que associam o seu produtor a cada produto científico e seu significado (como logo ou techné).

2 Enquanto campo específico, o campo científico reproduz-se em processos de troca com os campos que conformam um mundo dominado pela mercadoria e pelo capital, marcado por isso pela corrida contínua e compulsiva para novos níveis de produtividade e competitividade e as necessidades políticas de controlar os efeitos deletérios de tal dinâmica sobre o homem e sobre a natureza.
} 
atribuem a agentes e setores preestabelecidos uma primazia quase natural nos processos inovativos. Assim, a empresa e o empresário portadores das atitudes tradicionais do industrialismo capitalista são o foco da compreensão e da ação. O resultado tem sido uma dinâmica que aguça os riscos ambientais e aprofunda as mazelas sociais (Costa, 2005).

Parece haver, no atual governo, a oportunidade de mudanças importantes no quadro organizacional. Tal oportunidade constituirá, de fato, inovação, à medida que novos conceitos e mecanismos de gestão pública para o desenvolvimento possam preencher as novas organizações. Os atuais avanços na discussão do desenvolvimento (endógeno) fornecem novos conceitos, os quais, deslocando a centralidade do agente individual (empresa ou empresário) nos processos de desenvolvimento para as redes e aglomerados, permitem redefinir o objeto da (inter)ação pública para o desenvolvimento.

A noção de Arranjos e Sistemas Produtivos e Inovativos Locais faz parte desse acervo conceitual. Discorrendo sobre as possibilidades do uso do conceito no caso de uma nova institucionalidade para a ação federal na Amazônia como fundamento de inovações institucionais de grande alcance -, busca-se contribuir com a compreensão do processo da sua constituição, no Brasil, como techné - como instrumento de poder que possa ser acionado para o desenvolvimento.

\section{As percepções e os desafios da realidade na Amazônia}

A Amazônia tem sido foco da atenção mundial como natureza e como sociedade. Na primeira condição coloca-se em relevo a importância da maior floresta tropical do planeta como um acervo de biodiversidade e como base de prestação de serviços ambientais para a estabilização do clima global. Na segunda condição ressaltam-se os usos da base natural da região que se fazem (a não ser nas poucas exceçôes sempre lembradas) pondo em risco tudo o que se poderá obter de uma utilização mais qualificada - nas expressões correntes, racionais das suas características naturais e dos seus atributos locacionais. A conclusão é que a dimensão social da região, incluindo as intervenções políticas, constitui um paradoxo por realizar-se destruindo, em nome dos ganhos presentes de poucos, os mais preciosos trunfos para um futuro melhor para todos (Costa, 2005). 
Há realismo e equívocos nessa proposição, cuja consideração é imprescindível à discussão sobre uma nova forma de atuação governamental na região e sobre as inovações institucionais para isso necessárias.

São reais os riscos ambientais de muitas das práticas econômicas que se detectam na região, a par de prejuízos inquestionáveis ou benefícios sociais discutíveis. Mas é falso considerar irracionais os processos decisórios privados que fundamentam tais usos, ou sem sentido os cálculos de custo-benefício que nesse nível se processam. O justo é expor os dilemas aí vivenciados, para tratálos institucionalmente: mediante necessidades presentes que só conseguem ser atendidas por usos tradicionais (insustentáveis) da base natural, usos modernos (sustentáveis) que se apresentam como promessa de atendimento das necessidades futuras serão sempre postergados. ${ }^{3}$ É função do Estado, na Amazônia, atuar no sentido de anular o hiato de tempo existente entre formas modernas (porque sustentáveis) de uso dos recursos naturais da região e as necessidades cotidianas de suas populações.

É pertinente, por outra parte, a percepção de que muitas das intervenções estatais se fizeram na região corroborando práticas ambientalmente deletérias, aprofundando mazelas sociais, excluindo os mais necessitados e confirmando o poder econômico e político dos mais fortes. É justo, ainda, argumentar que tais ações resultaram de um certo conteúdo patrimonialista que tem marcado, com raízes profundas, o Estado brasileiro, vinculando-o a privilégios de segmentos sociais específicos. Mas não é certo presumi-lo cristalizado nessa condição. É possível e necessário tornar o Estado na Amazônia permeável à pluralidade de forças que expressam a diversidade social e cultural da região, dotando-o de mecanismos que o façam eficiente como indutor de desenvolvimento pela correção das desigualdades econômico-sociais.

É certo que atores privados, com o suporte de instituições do Estado, têm historicamente aportado a região com matrizes tecnológicas inadequadas, pois como a mentalidade de seus operadores, foram forjadas na relação com outros ecossistemas. Tais matrizes desenvolveram-se pelo esforço da ciência em criar

\footnotetext{
A hipótese de que avançam procedimentos tecnológicos (cada tecnologia implica-ou, em perspectiva mais radical, é -, sempre, uma relação particular com a natureza) concorrentes que, numa perspectiva de longo prazo, poderiam conduzir a região a um lock-in baseado em trajetórias inferiores, seja do ponto de vista econômico, seja da perspectiva ambiental ou social, deve orientar, cada vez mais, esforços de pesquisa. Para tanto, as indicações teóricas de Arthur $(1988,1994)$ são de extrema valia.
} 
sistemas botânicos homogêneos para maximizar a produção de biomassa por uma lógica de industrialização da agricultura fortemente assentada em bases mecânico-químicas (Goodman et al., 1989; Romeiro, 1998). As técnicas daí derivadas, por serem aparatos de padronização, negam o capital natural contido na diversidade biológica. Por seu turno, as mesmas características ecológicas da região que explicam sua gigantesca biodiversidade negam essas matrizes, reduzindo dramaticamente os ciclos de vida e a economicidade de suas técnicas. Um terceiro macrodesafio será, pois, o de alterar as pautas das instituições de Ciência \& Tecnologia na região para que, atuando orientadas pelo princípio da diversidade, em substituição ao da padronização e da homogeneidade, possam produzir técnicas ajustadas às necessidades regionais.

Em resumo: há, como ethos, um ambiente institucional conservador na perspectiva de um desenvolvimento com maior esperança de sustentabilidade. A institucionalidade é tradicional, porque assentada sobre uma razão técnica incapaz, por viés de visão de mundo, ou por insuficiência da forma de conhecer e de lidar conceitual e operacionalmente com o "valor" da diversidade (cultural e ambiental) para um desenvolvimento duradouro na região, desaparelhada para tratar com os agentes capazes de gerir diversidade, desaparelhada também para lidar com as manifestações e resultados locais dessas habilidades. Ademais, o tradicionalismo tecnocrático tem estatuto político: alimenta-se e é recompensado, arregimentando poder, ao corroborar com o status quo, ao atuar validando visões de mundo e ações que confirmam as formas temerárias e iníquas de desenvolvimento.

\section{Inovações institucionais: voluntarismo e política - planejamento}

Diante de tais desafios, inovaçóes institucionais para um desenvolvimento de novo tipo na região deverão se fazer minimizando as contradiçôes que, por uma parte dissociam desenvolvimento econômico e desenvolvimento social e, por outra, tornam o desenvolvimento uma ameaça a fundamentos naturais únicos e preciosos. O objetivo deverá ser, pois, o de um progresso social com eqüidade intra e intergerações, expresso por uma eficiência econômica que tenha as especificidades naturais e culturais da região como aliadas e, por isso, seja sustentável. 
Trata-se de promover a adequação entre as necessidades inerentes a um desenvolvimento moderno, voltado para a emancipação e inclusão sociais das grandes massas, com os potenciais e limites das base naturais e culturais presentes na Amazônia e, portanto, de construir bases institucionais para a estratégia de promover um desenvolvimento de base local, dependente e formador de capital humano e social, tecnologicamente baseado no uso denso de conhecimento tácito e codificado dos recursos naturais regionais. Portanto, um desenvolvimento irradiador de capacidades difusas, fundamentos de um progresso amplo e socialmente enraizado e, por isso, sustentável.

Carecer-se-ia, isto posto, de uma nova institucionalidade, cujo centro estratégico dispusesse dos fundamentos normativos que lhes permitissem o amplo leque de possibilidades enfeixadas em duas grandes capacidades - as capacidades de um novo sistema de planejamento para o desenvolvimento regional:

- a capacidade de discernimento macrossocial por visão integrada das dinâmicas econômicas e sociopolíticas com seus fundamentos naturais; e

- a capacidade de mediação das perspectivas de desenvolvimento dos sujeitos sociais - de internalizá-las como fundamento de gestão pactuada.

\subsection{A capacidade de conhecer de modo complexo - novas leituras de totalidade}

Uma institucionalidade nova deverá basear-se no melhor conhecimento possível sobre a sociedade e a economia amazônicas e sua base natural. Para tanto necessitará de capacidade própria, que lhes faculte o diálogo crítico e atualizado com as concepções modernas de desenvolvimento que hoje pautam a pesquisa de fronteira das ciências da sociedade e das ciências naturais, onde se destacam as patrocinadas pelas novas teorias institucionais, pelas teorias do desenvolvimento endógeno, pelas teorias evolucionárias das trajetórias tecnológicas, pelos esforços de determinação do peso da cultura e das redes sociais e do papel da especificidade ecológica na capacidade competitiva dos lugares, regiōes, etc. Nesse esforço encontrar-se-ão as ferramentas para operar valorizando as economias locais, discernindo quanto ao "valor" das suas disponibilidades e carências em termos de capitais social, humano e natural (Costa, 2001). 
O (re)conhecimento complexo da realidade permitirá, por seu turno, o acompanhamento eficiente do desenvolvimento regional por indicadores que por uma parte contemplem as esferas econômica, social e ambiental e, por outra, permitam observar os níveis micro, meso e macrorregional.

\subsection{Internalizar as perspectivas de desenvolvimento dos sujeitos sociais nos processos decisórios da ação federal - a constituição de um sistema de planejamento e gestão compartidos}

Uma nova institucionalidade deverá promover a democratização do processo decisório que formata a intervenção desenvolvimentista do Governo Federal na Amazônia. Para tanto, deverá conter mecanismos para uma incorporação dinâmica e qualificada de demandas dos atores sociais coletivos, por meio das representações de grupos relevantes no fundamento produtivo (econômico e social) e reprodutivo (econômico, social, político e cultural) do todo social.

Deverá fazer uma incorporação dinâmica das demandas sociais por mecanismos que considerem as dimensões de tempo e lugar do desenvolvimento. O processo de participação deverá permitir, assim, por um lado, adaptações evolutivas de trajetos de desenvolvimento - para isso terá que ser regular e recorrente, efetivando-se em timing apropriado; por outro lado, dado que essas trajetórias de desenvolvimento são espacialmente referidas, deverá se fazer estreitamente vinculado a lugares e regiōes.

Deverá fazer uma incorporação qualificada, porque derivada de participação que considera o melhor conhecimento prévio disponível do ambiente natural, social e econômico de onde partem as demandas e aonde se projetarão os efeitos de seu atendimento, dotando o processo decisório de recursos de aprimoramento e reversibilidade. É possível, a partir daí, indicar rumos aos agentes privados e públicos, desenvolvendo tarefas de coordenação para cuja efetividade mecanismos adequados de financiamento deverão ser acionados.

Capacidade de indicar rumos. Uma nova institucionalidade deverá ter capacidade de prover direção, compatível com o sentido estratégico de um novo desenvolvimento, à ação de agentes privados e de governos locais na Amazônia. Nesse ponto, tão importante quanto dispor de mecanismos de financiamento, é ter capacidade institucional para formular propostas de referência, ex ante e 
ex post dos momentos-chave dos processos decisórios (antes e depois do ano agrícola, antes e depois das estações de pesca, etc.). Uma proposta de referência, que pode ser apresentada na forma de um plano de ação, com linhas de investimentos e crédito, além de políticas públicas consistentes, ou simplesmente na forma de relatórios e diagnósticos que apontem consistentemente para tendências e oportunidades, deverá sempre ser um instrumento de convergência entre o que se sabe sobre o lugar e a forma das ações das quais se espera derivar o desenvolvimento moderno e os resultados da incorporação dinâmica e qualificada das perspectivas de desenvolvimento dos sujeito sociais. Uma vez produzida, esta peça deverá se constituir em parte integrante, em momento particular e ativo, tanto da discussão geral sobre possibilidades e formas de desenvolvimento de novo tipo, quanto da percepção particular de cada sujeito social, de cada ator, de cada agente que participa do processo.

Igualmente importante será a capacidade de colocar suas propostas de referência na agenda de todos os agentes, não apenas daqueles que participaram efetivamente - direta ou indiretamente - dos processos de sua formulação. Parte constitutiva dessa capacidade é a difusão dos indicadores, avaliações e estudos intermediários que fundamentaram as propostas de referência. Esse amplo conhecimento é parte do poder orientador das propostas. O papel da comunicação social é, aqui, central.

Capacidade de coordenação. Não raro se sucumbe à tentação de interpretar o desafio da coordenação da ação federal na região como uma obviedade administrativa, passível de se fazer a partir de delegação formal, de vontade ou de força política. A história dos órgãos de desenvolvimento regional no Brasil e no mundo mostra que não basta a "vontade", a "habilidade" ou, mesmo, a "força” política para que a coordenação aconteça, dado que há fortes fundamentos para a descoordenação. De modo que, uma nova institucionalidade para o desenvolvimento da Amazônia não deve se fundar sobre as ilusões da coordenação formal, derivada de uma hierarquia normativa, com poucas possibilidades de efetivação. Deve sim, partir do princípio de que a capacidade de prover direção à ação federal na região deverá ser conquistada pela qualidade das suas propostas de referência, pelo efeito crítico dos seus mecanismos de monitoramento e avaliação, pela capacidade desses mecanismos atingirem a menor escala possível, pela criação de oportunidades formais de confrontação 
entre o dever (das propostas de referência) e o ser (dos indicadores de avaliação das dinâmicas econômicas, sociais e ambientais) e pela ampla divulgação de tudo isso. Sobre este último ponto convém a consideração do argumento de que uma ação descoordenada tem maior chance de ser corrigida se o seu responsável for julgado pela opinião pública. Isso é mais efetivo que "reprimendas", sobretudo se provém de instância institucional que não tem qualquer poder na definição de orçamentos. É que, mediatizado, o "agente descoordenador" deverá pagar com perda de votos e respeitabilidade pública o que tentou ganhar (no geral, também votos) com a transgressão. Ele terá um cálculo de custobenefício a fazer que provavelmente favorecerá a direção e à coordenação.

Os mecanismos de financiamento são complementares à capacidade efetiva de coordenação, isto é, são ferramentas da capacidade precedente e superior de coordenar, devendo estar a esta subordinados. O processo de construção de um projeto moderno de desenvolvimento exige formas próprias de financiamento, as quais, por suposto, não podem depender de forças ou razões não-modernas, associadas a agentes que não conseguem (por suas posiçóes objetivas na corpo social ou pela história que delimitou suas subjetividades) pensar nem agir modernamente. O Fundo Constitucional de Desenvolvimento do Norte (FNO) tem características que o tornam uma inovação institucional capaz de financiar propósitos modernos de desenvolvimento, na perspectiva aqui colocada. $\mathrm{O}$ Fundo de Desenvolvimento da Amazônia (FDA), por seu turno, requer reformulações de grande envergadura, do mesmo modo que os mecanismos de renúncia e incentivos fiscais.

Um projeto moderno de desenvolvimento não se faz com instituiçôes tradicionais. Uma intervenção do Estado com o propósito de promover um desenvolvimento de novo tipo na Amazônia é tarefa exigente em conhecimento (novos paradigmas), em capacidade de formulação estratégica (novo planejamento e gestão institucional), em capacidade de interação social (novo planejamento do desenvolvimento regional), em capacidade de formação de opinião (nova comunicação), em nova capacidade de financiamento (democratização do acesso a fundos públicos) e em capacidade de condução política (projeto de direção, no sentido gramsciniano). 


\section{Arranjos e Sistemas Produtivos e Inovativos Locais - logo e techné}

A noção de Arranjos e Sistemas Produtivos e Inovativos Locais (ASPIL) oferece à razão possibilidades de visualizar a existência e reprodução social nas relaçôes que integram a sua esfera "propriamente" econômica com as esferas social e política (capital humano: nível de cultura e de habilidade dos cidadãos; capital social: nível das organizações da sociedade civil e sua capacidade de gerar e aplicar novos conhecimentos), expressas em totalidades referidas necessariamente a localidades concretas.

Às perspectivas que associam tais arranjos em níveis de sistematicidade (reprodução virtuosa nos termos do capitalismo) próprios das condições das realidades industriais mais avançadas (Porter, 1989), Cassiolato e Lastres (1999, 2003) oferecem a visão mais geral de que, em qualquer realidade social do capitalismo, submetida a tensões para mudar, a dinâmica de ajustamento produtivo e reprodutivo no uso das disponibilidades (repita-se, sempre locais) de trabalho, de capital físico e natural implica, isto é, requer e cria, fundamentos institucionais de cooperação entre as unidades mais irredutíveis (unidades produtivas e de consumo), canais de acesso dessas unidades ao saber codificado ou tácito necessário à inovação, tecnológica ou social, e de elementos de governança (nódulos estratégicos de coordenação), sejam eles formais ou informais, maduros ou insipientes. Essa necessária estruturação constituiria os Arranjos (podendo ser ou vir a ser Sistemas) Produtivos (podendo ser ou vir a ser Inovativos) Locais.

Tal noção é atrativa como logo, heurística e ciência. Ela é atrativa também como conhecimento, pelo poder de síntese real-concreta (uma expressão inteligível da complexidade - no sentido metodológico - da realidade social, sem concessões significativas a reduções mecânicas) que oferece. Nessa condição, ela permite estabelecer o lugar e nomear, concretamente, ${ }^{4}$ sujeito e objeto da dinâmica do desenvolvimento.

\footnotetext{
4 melhor aproveitamento dessa possibilidade exige a consideração do sentido da relação concreto-abstrato, isto é, da dialética da construção do "concreto" como produto do pensamento em contexto historicamente delimitado e, assim, a construção do concreto como "concreto pensado", tal como já enunciava Marx em seu mais mais denso texto metodológico (Marx, 1968). A atualidade metodológica dessa "aventura crítica", o nível de convergência de suas proposições com as questões de complexidade que hoje emergem dos esforços no tratamento das relações açãoestrutura, onde se incluem os programas heterodoxos da economia e os programas mais avançados da sociologia e de outras ciências da sociedade, pode ser avaliada em Bensaïd (1999).
} 
A noção é (por isso) também atrativa como techné: ou seja, conhecimento capaz de orientar intervençôes objetivadas, tecnologias de controle e coordenação social com vistas a, por exemplo, metas estratégicas de devir social, de desenvolvimento, se quiser, sustentável. Porque se (e o sujeito aqui oculto é sempre coletivo, social) se conhece lugar, sujeito(s) e objeto(s) das formas de reprodução social, se se vislumbram os nexos que os integram em processos virtuosos que transcendem as contradições de última instância (no sentido de Marx em $O$ Capital), internas a cada unidade produtiva (antagonismo capitaltrabalho) e externas a elas (concorrência e lei do valor), poder-se-ia atuar sobre eles, fortalecendo-os, suprindo carências objetivas e tornando-os cada vez mais densos do autoconhecimento produtor da ação comunicativa (Habermas, 1995) que, minimizando os problemas de mensuração/configuração dos contratos, dos pactos (North, 1981; Williamson, 1985), facilitam a cooperação.

Precisamente aqui a noção de ASPIL ganha suas duas existências, como logo e como techné. Existências necessariamente associadas, dado que, não obstante timing e premências (tensóes) próprias, condicionam-se mutuamente e legitimam-se uma à outra na direção de saber normal (Kuhn, 1982) e/ou instrumental (Habermas, 1995).

\subsection{Os Arranjos e Sistemas Produtivos e Inovativos Locais e uma nova institucionalidade para o desenvolvimento na Amazônia - uma oportunidade da observação integrada e da ação integradora}

A noção oferece uma oportunidade teórico-metodológica de visão integrada das esferas econômica, sociocultural e natural podendo, assim, fundamentar a explicitação de referências estruturais compatíveis com as necessidades da nova institucionalidade: ela permite a formação cumulativa de conhecimento complexo e totalizante (holístico); permite a localização e acesso, e, portanto, pode viabilizar estratégias de interação sistemática dos atores relevantes para um programa de ação (comunicativa) com vistas à eficiência do conjunto - e, por isso, do lugar onde ele se materializa; nesse ponto, poderá ajudar a construir o lugar institucional em que se comparte a gestão pública, em que se abre o processo decisório das intervençôes, para um leque, tanto mais amplo de atores, quanto mais se conheça, pela ação da pesquisa, o conjunto, quanto mais, tam- 
bém, se dêem a revelar, por sua própria ação, cada parte; poderá fundamentar, ainda, a base do acompanhamento e avaliação das políticas públicas para o desenvolvimento.

Mas há questões a considerar. A primeira diz respeito às características da estrutura e sistemática organizacionais necessárias para garantir os fluxos de informação e a fluidez dos inputs resultantes das avaliações e pactos de prioridades que derivam de uma tal construção. A segunda diz respeito à estruturação organizacional capaz de lidar com um número grande desses arranjos, quando se pensa em escala regional.

\subsection{Os ASPIL e as escalas do desenvolvimento}

As possibilidades da noção de ASPIL fundamentar um sistema de planejamento regional para o desenvolvimento sustentável da Amazônia são reais. Há riscos, contudo, a considerar. Destaco, em primeiro lugar, o de que, apoiandose na legitimidade de sua concretude, a noção se constitua, ela própria, em redução criticável: negando a validade de expressões mais abstratas (cadeias, setores, pólos), ela se pretenda suficiente para descrever o mundo. Ou ela se pretenda uma oposição exteriorizada dessas expressões.

Se este não é um risco tão claro na sua existência como logo, é seguramente um problema na sua existência enquanto techné. Tal problema associa-se às questôes tratadas na literatura como das relações micro/macro (parcialmente formuladas por Coutinho, 2004) e local/global (Schmitz, 2003; Humbert, 2003). Há que se tratar, contudo, de modo mais preciso a questão.

As perguntas pertinentes são:

1) se o ASPIL é mesorrealidade local, qual a macrorrealidade que lhes corresponde?

2) igualmente, sendo mesorrealidade, que microcosmos são a ele subjacentes?

As respostas à primeira questão exigem percorrer dois caminhos. Primeiro, o ditado pela percepção da macroeconomia como um momento da reprodução objetiva da sociedade - como um sistema de realização da condição de 
valor de uso das mercadorias; aqui adotaríamos, por assim dizer, a ótica (da alocação) do produto na definição da escala. Segundo, o exigido pela percepção da macro economia como um momento de realização dos constrangimentos monetários; aqui realçaríamos a ótica (da alocação) da renda na definição da escala (esta a dimensão macro que trata Coutinho, 2004).

Responder à segunda questão exige observar, também, dois aspectos: o ditado pela necessidade de tratar as diferentes racionalidades que organizam os processos decisórios dos diversos agentes abarcados na categoria de ASPIL e as razôes dos agentes na realidade dos ASPIL. Há que se considerar, pois, os capitais (simbólicos e objetivos, seguindo Bourdieu, 1989) específicos, cuja acumulação é o objeto dos diferentes atores dentro do mesmo ASPIL e o sentido real-concreto desses capitais.

\subsection{Macrorrealidades dos ASPIL - produto, setores e pólos}

Se o ASPIL é meso-realidade local, qual a macrorrealidade que lhe corresponde? A condição de subsistema do ASPIL (o fato de que, como realidade produtora de mercadorias, projeta-se em mundo extralocal, e só existe mediado por este mundo) apela a abstrações "econômicas" mediatas. A sua condição de natureza (o fato de ser uma componente de uma estratégia reprodutiva e, portanto, da divisão do trabalho de um grupo social concreto, vivendo em uma localidade concreta) apela a uma abstração "geográfica" imediata.

Para a realidade não-local (que é constitutiva da realidade local), o ASPIL $x$ do lugar $A$ (o arranjo que produz $x$ no lugar $A$ ) é um entre um conjunto de $A \operatorname{SPIL}(s)$ que produz $x$ nos lugares de $A$ até $N$. Para a realidade local A, o ASPIL $x$ é o único responsável pela produção de $x$ no lugar A. Ele é parte, assim, de um conjunto de ASPIL(s) que, no lugar A, produz um conjunto de $n$ produtos, dentre os quais encontra-se $x$. A noção de ASPIL pode, portanto, compor inicialmente a noção sistêmica de setor (tornando este último sua projeção macroeconômica), do mesmo modo que um setor pode ser logicamente decomposto em N ASPIL(s) de mesma natureza. Ela pode também compor ou decompor a noção fortemente demarcada geograficamente de pólo, entendendo estes aglomerados como agregação sinérgica de $n$ ASPIL(s) de natureza diferente. A economia regional (uma totalidade macro de referência) pode ser, assim, representada por um conjunto de setores, por um 
conjunto de pólos, por um conjunto de ASPIL(s) - este o denominador comum de todos os termos.

A compreensão da realidade econômica exige, pois, as três referências estruturais (além das referências irredutíveis de empresas e consumidores): o ASPIL, o setor e o pólo. Uma via para transitar do nível mais elementar do ASPIL, para os níveis mais abstratos, do setor e do pólo, seria a composição/decomposição com base no primeiro.

Estas seriam operações formalmente corretas, contudo, teórica (e praticamente) insuficientes. Isso porque, um setor, como uma projeção macroeconômica de ASPIL(s) de mesma natureza em uma delimitação geográfica superior à local, é mais que a soma dos ASPIL(s). Nesse nível (re)estabelecemse questôes "amenizadas" no contexto do ASPIL, sobretudo as que resultam das regulações da relação capital/trabalho (sindicatos de trabalhadores e patronais se estruturam por setor) e da relação do tipo de atividade (valor de uso) com o conjunto da produção social - divisão social do trabalho nacional e internacional. E surgem outras, as que só se manifestam compreensivamente e, portanto, só conseguem ser tratados, como problemas da reprodução social, como tal apenas no contexto dos constrangimentos objetivos do conjunto da produção de mesma natureza (da região, do país, do mundo) com o conjunto da produção de toda natureza (da região, do país, do mundo).

Do mesmo modo, um pólo é mais que a soma dos ASPIL(s) que o compõem - há transcendências e carências que derivam do conjunto de ASPIL de natureza diferente que fazem o pólo, o lugar. Nesse nível, as externalidades, tanto as positivas - o grau de educação, as carências infra-estruturais, as disponibilidades de conhecimento de base, o grau de organização de consumidores, produtores, trabalhadores -, quanto as negativas (destruição da base natural, cultura política tradicional) se manifestam com toda sua plenitude em dimensão local, em um pólo - na totalidade, diga-se, na integridade das suas dimensões urbana e rural.

Ter-se-ia de agregar métodos para complementar a visão do setor naquilo que só seu nível de abstração permite observar - tal e qual o que se passa com a dimensão macro do lugar, do pólo, da aglomeração que transcende aos seus ASPIL(s) constitutivos.

Na visão da ação política, cada referência estrutural implica formas distintas de pactuamento, para tratar de questões só perceptíveis nas respectivas escalas. A consciência social dos problemas e potencialidades, os quais têm, todos, 
(mesmo que transmutados) seu momento mais concreto no plano do ASPIL, só consegue constituir-se, como conhecimento, no nível adequado de abstração; como pacto político, no tipo de organização capaz de se orientar por percepções e modelos mais abstratos.

\subsection{Macrorrealidades dos ASPIL - constrangimentos monetários e cambiais}

Se o ASPIL é mesorrealidade local, qual a macrorrealidade que lhes corresponde? Para Luciano Coutinho (2004), aquela conformada pela relação entre taxa de inflação, taxa de câmbio, taxa de juros e carga fiscal: a realidade dos constrangimentos monetários que afetam a rentabilidade relativa presente dos ativos reais e financeiros e balizam as expectativas futuras quanto à eficiência dos investimentos atuais. Pressupostamente, o ASPIL não constituiria uma mediação diferenciadora da relação entre esses constrangimentos e os agentes. ${ }^{5}$ Sobre isso retornaremos adiante.

\subsection{Microcosmos e ASPIL - capital humano e trabalhadores}

A noção de ASPIL considera como agentes produtivos as empresas. Nessas, o trabalho explicita-se, na condição de capital humano. Como tal, todavia, é objeto: ele é tratado como um dado condicionado por externalidades e como uma variável, todavia passiva, resultado da disposição unilateral de seu sujeito: a empresa/o empresário. Considera-se a importância da formação de capital humano, enfatiza-se, mesmo, o conhecimento tácito e não codificado dessa força produtiva, porém ela, como referência sociológica concreta, não encontra expressão na categoria.

\subsection{Microcosmos e ASPIL - arranjos urbanos e desarranjos rurais}

A noção de Arranjos e Sistemas Produtivos e Inovativos Locais aplicada a realidade de base agrária, tende a privilegiar sua dimensão urbana. É que se

5 Há duas especificidades institucionais nesse ambiente, no que se refere à Amazônia. Há, na região, fundos para investimento em que a taxa de juros pode se situar abaixo do mercado e há legislação de incentivos e concessões fiscais para o desenvolvimento regional. 
enfatiza a produção industrial, sua tendência à especialização e ao conseqüente aprofundamento da divisão social do trabalho e o papel que aí desempenham as inovaçôes. Como foi mencionado, trata-se de delimitar as condições de existência e evolução do ASPIL $x$, sendo $x$ um único valor de uso.

Tal viés não apresentaria maiores conseqüências em contextos em que, na agricultura, isto é, no fundamento rural do ASPIL, ocorresse (sem crises) processos correspondentes de industrialização e especialização. Tal não é caso da realidade da realidade contemporâneas em geral, muito menos das que se encontram em áreas tropicais: aqui, a diversidade da base rural parece constituir uma força produtiva, cujo obscurecimento no geral cobra um preço - não importando se pago pelos que ficam, em processos contemporâneos, ou se pago pelas gerações por virem.

De modo que, ao ASPIL $x$ em A corresponde unidades produtivas que administram um Sistema de Produção Rural (SISR) com $m$ outputs, entre os quais encontra-se $x$. A visão do ASPIL integrada por $x$ implica, assim, em uma visão mutilada, parcial, do conjunto de gestores de SISR. Uma observação integrada por SISR, implicaria numa observação que integre os $m$ ASPIL que realizam sua produção.

Considerando as questóes associadas à sustentabilidade dos processos de reprodução social na Amazônia, considerando o papel que aí desempenham as formas de uso da base natural, essa dupla leitura é necessária.

\subsection{ASPILs, setores, pólos, sistemas rurais: métodos de leitura}

É fundamental visualizar o impacto macroeconômico - na ótica do fluxo de produtos - de um ASPIL; é importante situá-lo na divisão social do trabalho posicionando-o como setor de uma economia local - um pólo - e como setor (ou parte) de uma economia regional ou nacional. Do mesmo modo, importa observá-lo como um nexo da relação urbano-rural - tanto como um vetor a configurar, como um momento, a realização de um sistema rural, quanto o contrário.

Para tanto, é necessário que se desenvolvam métodos de leitura adequados. Métodos de contabilidade social ascendente tornam-se, aqui, fundamentais.

Foram desenvolvidas, no Núcleo de Altos Estudos Amazônicos, da Uni- 
versidade Federal do Pará, metodologias para a produção de contabilidade social capaz de ler isolada e integradamente tanto os ASPIL quanto os SISR, em nível local ou regional. As Contas Sociais Alfa - CS $\alpha$ (Costa, 2002) são obtidas por processamento que integra as disponibilidades estatísticas do IBGE quanto aos atributos estruturais e quanto às variaçôes conjunturais das economias locais e os resultados de pesquisa primária (metodologias próprias de levantamento das configurações de rendes de produto e formação de preço) sobre as estruturas das cadeias produtivas e da formação dos preços, seguindo o algoritmo abaixo.

Obtém-se a contabilidade social de uma economia de $k$ produtos cujos fluxos fazem-se por $n$ agentes agrupados em $m+1$ posiçôes no sistema produtivo e distributivo, em que a $m+1$-ésima posição é a do Demanda Final, pela equação

$$
X_{i j}=\sum_{i=1}^{m} \sum_{j=1}^{m+1} \sum_{v=1}^{k} q_{i j v} . p_{i j v}
$$

em que $v$ é o produto, $j$ o setor que o compra e $i$ o setor que o vende.

E, se se faz vigorar $g$ atributos geográficos e e atributos estruturais, a equação (1) seria, então, resultado da agregação de um número g.e de submatrizes, cada uma delas composta por

$$
X_{s r i j}=\sum_{s=1}^{g} \sum_{r=1}^{e} \sum_{i=1}^{m} \sum_{j=1}^{m+1} \sum_{v=1}^{k} q_{s r i j v} . p_{s r i j v}
$$

em que $r$ seria o atributo estrutural (ASPIL $x$ a $z$, por exemplo) e $s$ o atributo geográfico (município A ou conjunto de município A a $\mathrm{N}$ ).

Os elementos das matrizes de totalização para os atributos geográficos seriam

$$
X_{s i j}=\sum_{s=1}^{g} \sum_{i=1}^{m} \sum_{j=1}^{m+1} \sum_{r=1}^{e} X_{r i j}
$$


e, para os atributos estruturais, seriam

$$
X_{r i j}=\sum_{r=1}^{e} \sum_{i=1}^{m} \sum_{j=1}^{m+1} \sum_{s=1}^{g} X_{s i j}
$$

culminando-se com uma matriz totalizadora do conjunto, cujos elementos seriam

$$
X_{i j}=\sum_{i=1}^{m} \sum_{j=1}^{m+1} \sum_{r=1}^{g} X_{r i j}=\sum_{i=1}^{m} \sum_{j=1}^{m+1} \sum_{s=1}^{e} X_{s i j}
$$

É possível indexar os resultados no tempo. É possível, também, integrar os resultados dessa contabilidade com matrizes setoriais mais abrangentes (Costa, 2002).

\subsection{Da submissão de constragimentos monetários e fiscais às necessidades de um desenvolvimento moderno e o papel dos ASPILs}

Acima mencionou-se que os constrangimentos fiscais e monetários recairiam diretamente sobre os agentes sem mediação dos ASPIL (cf. Coutinho, 2004). Entretanto, onde é possível criar condições específicas por mecanismos de política econômica, como é o caso da Amazônia, haveria como "regionalizar" tais constrangimento (regulando o custo do dinheiro por linhas de crédito de fomento ou reduzindo a carga fiscal) condicionando-os em parte ao mecanismo de planejamento e gestão para o desenvolvimento.

É possível demonstrar (Costa \& Santana, 2002) que maximiza-se a transformação do excedente gerado na região em produto e renda local se: 1) substitui o princípio da renúncia ou concessão fiscal para empresa pelo princípio da renúncia ou concessão fiscal à região; 2) se assim se procede, a concessão fiscal global é repartida em dois componentes: um diretamente assimilado pela empresa tributada, outra transferia a fundos públicos geridos localmente para criação de capacidade locais (os centros estratégicos da nova institucionalidade e seus 
mecanismos de concertação - de ASPIL, de setor e de pólo); 3) a parcela da empresa é condicionada a sua forma de participação no desenvolvimento moderno e sustentável que se cogita: tanto maior, quanto mais endógeno e ambientalmente prudente, etc.; e 4) como sistema de peso para internalizar no processo decisório das empresas os viéses de desenvolvimento e sustentabilidade, as condições necessidades das três referências estruturais de que vimos tratando: os ASPIL, os setores e os pólos.

\section{Conclusão}

Há a necessidade de uma nova institucionalidade para o planejamento do desenvolvimento na Amazônia, para o que a noção de Arranjos Produtivos Locais (APL) pode fornecer elementos importantes. A noção pode se constituir conceito-chave de uma estrutura de conceitos que de um lado permita a leitura integrada das escalas (micro, meso e macro) e das esferas (econômica, social e ecológica) da economia regional e seu desenvolvimento.

Assim, pode se constituir referência para a montagem de mecanismos de abertura do processo decisório, de pactuamento de prioridades para o planejamento do desenvolvimento e para o acompanhamento do processo de intervenção de governo.

Para tanto, torna-se necessário o desenvolvimento e implantação de novos instrumentos de leitura das realidades econômico-sociais, como uma contabilidade social capaz de captar a estrutura e a dinâmica das economias locais considerando sua constituição em ASPIL. É necessário também alterar as normas dos instrumentos de política de desenvolvimento regional de modo que sejam capazes de considerar as necessidades e potencialidades dos ASPIL, seus agentes e seus lugares.

Por último, mas não menos importante, a noção de ASPIL deve permitir leituras de mão-dupla da relação urbano-rural. 


\section{Referências bibliográficas}

Alier, J.M., De La Economia Ecologica al Ecologismo Popular, Barcelona: Içaria, 1994.

Arthur, W.B., "Competing technologies: an overview", in Dosi, G.; Freeman, C.; Nelson, R.R.; Silverberg, G.; Soete, L. (orgs.), Technical Change and Economic Theory, Londres e Nova York: Printer Publisher, 1988.

Increasing Returns and Path Dependence in the Economy, Michigan: The University of Michigan Press, 1994.

Bensaïd, D. Marx, o Intempestivo: grandezas e misérias de uma aventura critica, Rio de Janeiro: Civilização Brasileira, 1999.

Bourdieu, P., O Poder Simbólico, Lisboa e Rio de Janeiro: Difel e Bertrand Brasil, 1989.

, "O Campo Científico", in Ortiz, R., Pierre Bourdieu. Coleção Grandes Cientistas Sociais - Sociologia n.39, São Paulo: Editora Ática, p.122155, 1994.

Cassiolato, J.E.; Lastres, H.M.M., "O Foco em Arranjos Produtivos e Inovativos Locais de Pequenas Empresas", in Cassiolato, J.E.; Lastres, H.M.M. (orgs.). Pequena Empresa: Cooperação e Desenvolvimento Local, Rio de Janeiro, Relume Dumará, 2003.

, "Inovação, Globalização e Novas Políticas de Desenvolvimento Industrial e Tecnológico", in Cassiolato, J.E.; Lastres, H.M.M. (orgs.). Globalização e Inovação Localizada: experiências de sistemas locais do Mercosul, Brasília: IBCT/MCT, 1999.

Costa, F. de A., Ciência, Tecnologia e Sociedade na Amazônia: Questōes para o desenvolvimento sustentável, Belém: Editora Cejup, 1998.

, "As Ciências, o Uso dos Recursos Naturais na Amazônia e a Noção de Desenvolvimento Sustentável: Por uma interdisciplinaridade ampla", in Vieira, I.C.G.; Silva, J.M.C.; Oren, D.C.; D’Incao, M.A. (orgs.), Diversidade biológica e cultural da Amazônia, Belém: Museu Paraense Emilio Goeldi, 2001.

“A Dinâmica da Economia de Base Agrária do 'Pólo Marabá' (19952000): uma aplicação da metodologia de Contas Sociais Ascendentes (CSa)", Novos Caderno do NAEA, v.5, n.1, p.35-72, 2002. 
, "Questão Agrária e Macropolíticas na Amazônia: Novos momentos grandes desafios", Revista do Centro de Estudos Avançados, n.53, jan.-mar., São Paulo: USP, 2005.

Costa, F. de A; Santana, A.C., "Desenvolvimento Regional Sustentável e Incentivos Fiscais: um modelo alternativo para a Amazônia", Novos Caderno do NAEA, v.5, n.2., p.89-116, 2002.

Coutinho, L., "Regimes Macroeconômicos e Estratégias de Negócios; uma política industrial alternativa para o Brasil no Século 21", in Lastres, Cassiolato \& Arroio (orgs.), Sistemas de Inovação e Desenvolvimento, Rio de Janeiro: RedeSist, 2004.

Goodman, D.; Sorj, B.; Wilkinson, J., Da Lavoura às Biotecnologias: Agricultura e Induistria no Sistema Internacional, Rio de Janeiro: Editora Campus, 1989.

Habermas, J., Theorie des kommunikativen Handelns: v.1, Handlungsrationalität und geselschaftliche Rationalisierung, Frankfurt: Suhrkamp, 1995.

Humbert, M., Globalisation and Glocalisation: problems for developing countries and policu (supranational, national and subnational) implications, Rio de Janeiro: RedeSist, NT 08, 2003.

Kuhn, T., A estrutura das revoluçôes cientificas, São Paulo: Perspectivas, 1982.

Marx, K., "Die Methode der Politischen Ökonomie", in: Marx, K., Zur Kritik der Politischen Ökonomie, Berlim: Dietz Verlag, p.247-257, 1968.

North, D., Structure and Change in Economic History, Nova York, Londres: W. W. Norton and Company, 1981.

Porter, M.E., A Vantagem Competitiva das Naçôes, Rio de Janeiro: Editora Campus, 1989.

Romeiro, A.R., Meio ambiente e dinâmica de inovação na agricultura, São Paulo: FAPESP/ANNABLUME, 1998.

Sachs, I., Estratégias de Transição para o Século XXI: Desenvolvimento e Meio Ambiente, São Paulo: Studio Nobel/Fundap, 1993.

Schmitz, H., Local Upgrading in Global Chains, Rio de Janeiro: RedeSist, NT 06, 2003.

Williamson, O., The economic institutions of capitalism, Nova York: Free Press, 1985 . 